\title{
Relational Diversity and Neighbourhood Cohesion Unpacking Variety, Balance and In-Group Size
}

\author{
Ruud Koopmans \\ WZB Berlin Social Science Center
}

\author{
Merlin Schaeffer \\ University of Cologne
}

Please cite as: Koopmans, Ruud and Merlin Schaeffer. 2015. "Relational Diversity and Neighbourhood Cohesion. Unpacking Variety, Balance and In-Group Size.” Social Science Research 53:162-76.

\begin{abstract}
Ethnic diversity is typically measured by the well-known Hirschman-Herfindahl Index. This paper discusses the merits of an alternative approach, which is in our view better suited to tease out why and how ethnic diversity matters. The approach consists of two elements. First, all existing diversity indices are nonrelational. From the viewpoint of theoretical accounts that attribute negative diversity effects to in-group favoritism and out-group threat, it should however matter whether, given a certain level of overall diversity, an individual belongs to a minority group or to the dominant majority. We therefore decompose diversity by distinguishing the in-group share from the diversity of ethnic out-groups. Second, we show how generalized entropy measures can be used to test which of diversity's two basic dimensions matters most: the variety of groups, or the unequal distribution (balance) of the population over groups. These measures allow us to test different theoretical explanations against each other, because they imply different expectations regarding the effects of in-group size, out-group variety, and balance. We apply these ideas in an analysis of various social cohesion measures across 55 German localities and show that both in-group size and out-group diversity matter. For the native majority as well as for persons of immigration background, the variety component of diversity seems to be more decisive than has formerly been acknowledged. These findings provide little support for group threat and in-group favoritism as the decisive mechanisms behind negative diversity effects, and are most in line with the predictions of theories that emphasize coordination problems, asymmetric preferences, and network closure.
\end{abstract}

Keywords: $\quad$ Ethnic diversity, social cohesion, entropy, in-group favoritism, group threat

\section{Acknowledgements}

This research is part of the project "Ethnic Diversity, Social Trust and Civic Engagement", which is funded by the German Federal Ministry of Family Affairs, Senior Citizens, Women and Youth. Both authors have contributed equally to this article and the order of names is strictly alphabetical. Please direct all correspondence to: merlin.schaeffer@uni-koeln.de 


\section{Introduction}

In spite of a rich set of empirical findings, the overall picture on whether ethnic diversity and social cohesion are negatively associated remains inconclusive (Portes \& Vickstrom, 2011; Stichnoth \& Straeten, 2013). Two recent meta-analytic reviews show that studies focusing on specific measures of social cohesion, rather than abstract notions of generalized trust, as well as small-scale aggregate units, such as neighborhoods or cities, mostly find confirmatory evidence of a negative association (van der Meer \& Tolsma, 2014, Schaeffer, 2014). In striking contrast to this debate, social science research on organizations has produced a similarly lively debate on the economic benefits of ethnically diverse work teams (e.g. Page 2008). Here ethnic diversity is regarded as a driving factor behind innovation and problem solving. So is ethnic diversity enriching and beneficial or harmful and constraining for society? We believe that there is little to gain from charging the potential positive and negative consequences of diversity against one another. Instead, these complex findings highlight the necessity to study in an interdisciplinary way the mechanisms through which ethnic diversity is linked to valued outcomes such as engagement and trust, or innovation and efficiency.

We focus on the negative consequences of ethnic diversity for neighborhood trust and cohesion that have been documented in many studies. Over the last years, several theoretical approaches have been put forward to explain the potentially negative effects of ethnic diversity. We specify how these explanations can be linked to specific aspects of population heterogeneity and thereby tested against one another. However, we also explain why existing indices of population heterogeneity are not suited for such a task. First, the existing measures of the different aspects of population heterogeneity (true diversity, polarization, minority share and so on) are highly collinear, and can hence hardly be applied to test competing theories against one another (Schaeffer, 2013a). Second, the existing measures carry ambiguous meaning in at least two regards. First, diversity means fewer in-group members for majority members, whereas the opposite tends to be the case for minority members. Second, conventional diversity indices reflect, next to the in-group share, two components of outgroup diversity that they cannot disentangle: the variety of outgroups and the unequal distribution (balance) of the population over these groups. Against this background, we propose an alternative coherent measurement framework that relies on a decomposition of the overall population heterogeneity into group-specific a) in-group shares and b) out-group diversities. In addition, we show how c) generalized entropy measures can be used to test which of the group-specific out-group diversities' two basic dimensions matter most: variety or balance. 
Taken together, these measures allow us to test the different theoretical explanations against each other.

To empirically illustrate the merits of our decomposition of diversity, we use the German sub-set of the Ethnic Diversity and Collective Action Survey (EDCAS) with its roughly 7,500 respondents, who live in one of 55 theoretically and randomly sampled German cities and regions. As dependent variables, we investigate three indicators of neighborhood cohesion and an overall neighborhood cohesion scale. Our findings provide little support for group threat and in-group favoritism as the decisive mechanisms behind negative diversity effects, and are most in line with the predictions of theories that emphasize coordination problems, asymmetric preferences, and network closure, which are maximized where there are many small groups.

\section{Theoretical background}

Several theoretical approaches have been proposed to explain the potentially negative effects of ethnic diversity (for overviews see: Habyarimana et al., 2007, van der Meer \& Tolsma, 2014; Koopmans, Lancee \& Schaeffer, 2015). Evidence about the relative explanatory power of these competing theoretical approaches is needed, both for a deeper scientific understanding and for the development of successful policy interventions. Yet, most studies provide no evidence for the supremacy of one explanation over others. The so far existing attempts operationalize the competing mechanisms by linking them to different aggregate levels (e.g. Williamson, 2015; Dinesen \& Sønderskov, forthcoming), as (field) experimental treatments (e.g. Habyarimana, 2007; Koopmans \& Veit, 2014a), or via cognitive perceptions of diversity (Koopmans \& Schaeffer 2016). Most of these studies question the dominant view that feelings of group threat are the dominant force behind negative diversity effects.

Alternatively, the competing theories can be linked to specific aspects of population heterogeneity, as we will detail in the following. Our approach is broadly in line with van der Meer and Tolsma's statement that 'In the threat mechanism, rising relative out-group and decreasing in-group size primarily stimulate feelings of ethnic group threat. Feelings of anomie find their origin in diverse environments; the anomie mechanism stresses the lack of common language, identities, and values regardless of the size of the in-group itself' (van der Meer \& Tolsma, 2014: 464). But in line with Schaeffer (2013a), we identify a third position represented by scholars who emphasize polarization as particularly harmful. 
The majority of studies refer to theories of biases against out-group members, in particular group threat theory (e.g. Blalock, 1967; Olzak, 1992) and in-group favoritism (e.g. Tajfel \& Turner, 1986; Brown, 2000). From the viewpoint of these dominant theoretical accounts, it should mainly matter whether an individual belongs to a small minority group and is thus mostly surrounded by members of one or more ethnic out-groups, or belongs to the dominant majority and is therefore mainly surrounded by co-ethnics. In particular, scholars who refer to group threat theory argue that ethnic struggles for resources and symbolic representation compromise social cohesion (e.g. Hou \& Wu, 2009; Helbling, Reeskens \& Stolle, 2015). Accordingly, it is not ethnic diversity per se that undermines trust and cooperation, but simply out-group presence. Vice versa, it is the in-group share that matters for in-group favoritism, i.e., the drive to boost one's self-esteem via 'favourable comparisons that can be made between the in-group and relevant outgroups' (Brown, 2000: 747). Hence, for these approaches the in-group/out-group relation matters irrespective of whether the out-group is itself diverse or not. The group-specific in-group shares that have been used in some studies reflect this relational aspect (Bécares et al., 2011; Bakker and Dekker, 2012).

Some proponents of group threat theory object and argue that the most contentious situations are polarized, meaning those where two equal opponents face each other: 'Conflict is less likely in societies in which fractionalization is minimal or maximal' (Dincer, 2011, p. 291). Montalvo and Reynal-Querol (2005a, 2005b) base this claim on a formal game-theoretic rent-seeking model. Gould (2003) on the other hand explains that polarized situations are characterized by maximal ambiguity about group rank, i.e. who is the domonant party? For these proponents of group threat theory, threat should be comparatively low if out-group members are scattered across tiny fractions, i.e. a situation in which the overall out-group is too internally heterogeneous, divided and engaged in internal quarrels for it to be a significant threat to the in-group. One large homogenous out-group is in this view a much more formidable threat than a similarly sized diverse out-group population.

Scholars working on developing countries have proposed culture-based explanations according to which out-group fractionalization matters too - but in precisely the opposite direction. That is, a diverse out-group erodes social cohesion more than a (similarly sized) homogeneous one. If a person's ethnic background is associated with specific preferences, ethnic diversity could stir disagreement about how the common community life should look like, and which public goods should be provided. Williamson provides an illustrative example from her fieldwork on Somali migration to Lewiston, Maine (USA): 'Informants spoke of fights among neighbors about different tolerance of noise and contrasting sexual mores in 
which disagreements quickly become attributed to race' (Williamson, 2015: 74). According to collective choice theories, the potential for such disagreement erodes trust (Kimenyi, 2006; Page, 2008). If so-called asymmetrically distributed preferences lie at the heart of negative diversity effects, the most harmful ethnic composition is a truly diverse one, because the more divergent interests there are the more complicated and unlikely compromises on shared goals become. Two polarized groups can come to a compromise on at least a few shared goals more easily than can a large number of groups. We arrive at a similar conclusion if we conceive of ethno-cultural differences not as preferences, but as habituated routines of action and ways of doing things, which allow us to interact and communicate with others (Habyarimana et al., 2007; Desmet et al., 2012). Translation problems increase with the number of languages spoken. This means that coordination problems, too, are a function of true diversity rather than of polarization, where only two languages or ways of doing things have to be coordinated. Finally, there is the largely neglected role of social control, which may suffer from ethnically clustered networks (Miguel \& Gugerty, 2005). To the degree that ethnic boundaries are also reflected in network compositions, because people tend to associate with co-ethnics, ethnic diversity is also associated with lower network density, decreased social control, and (via this mechanism) lower levels of social cohesion. Again a truly diverse situation would be most problematic, because here the network would be maximally clustered. Some recent studies provide evidence of the relevance of these culture-based mechanisms also for the European and US American context (Koopmans \& Veit, 2014a; Williamson, 2015; Koopmans \& Schaeffer, 2016). In summary, all these culture-related obstacles (asymmetrically distributed preferences, coordination problems, and clustered networks) should find their climax in the limit case in which each person in a given context belongs to a different ethnic group with its own unique language, values, and isolated social network.

Unfortunately, existing diversity indices are unsuited to disentangle these different aspects of population heterogeneity (Schaeffer, 2013a). Accordingly, we need an alternative coherent measurement framework that captures these aspects separately and thereby allows to test the competing theories. In the following we will detail the flaws of existing diversity measures and propose an alternative coherent measurement framework.

\section{Dimensions of diversity and their measurement}

According to Stirling (2007) and Page (2010), all conceptualizations of diversity have in common that they deal with three basic properties: variation, balance and disparity. Variation 
refers to the number of categories or types, which in our case means the number of ethnic groups. Balance refers to how (un-)equally a continuous attribute (usually a population) is distributed over the categories - in our case, how similarly sized the population shares of the different ethnic groups are. Disparity, finally, refers to what actually distinguishes the categories from one another. ${ }^{1}$ In most European research on ethnic diversity, for example, ethnic categories are distinguished by nationality. A diversity index is a way of compressing information on the number (variety) and population shares (balance) of ethnic groups in a given setting into a single number. ${ }^{2}$ As in any discussion that distinguishes two core dimensions, we can derive four ideal-typical compositions (see Figure 1):

- Mono-ethnic or homogeneous settings are those in which there is, apart from perhaps a few deviant individuals, only one ethnic group. This composition is defined by the virtual absence of variety and extreme imbalance. Iceland before the recent arrival of immigrants is an example of such a mono-ethnic society.

- Quasi-monoethnic settings are those in which there are non-negligible minority groups, but the sizes of each of these minority groups are dwarfed by that of one strongly dominant majority. The situation in European immigration countries is generally a quasi-monoethnic one: a clear national majority is accompanied by a number of comparatively small minority immigrant groups. The commonly used diversity indices are badly suited to capture diversity in such contexts because in quasi-mono-ethnic situations they mainly pick up the balance dimension and hardly reflect the variety aspect of diversity.

\footnotetext{
${ }^{1}$ In its simple version, disparity refers to what distinguishes nominal categories from one another; but all categories are seen as similarly different from one another; Greeks are treated just as distinct from Egyptians, as Poles are from Argentinians. What such categories might be correlated with, but do not measure, is actual cultural diversity in norms, values, preferences, languages and meanings. This is the complex version of disparity. In this article we focus on the simple version of disparity - but our de-compositional approach to diversity can easily be extended to take more complex versions of disparity into account.

${ }^{2}$ Some use the level of segregation as a diversity measure. But whereas diversity relates to one contextual level, segregation always relates to two. The index of dissimilarity, for example, measures segregation as the percent of a group's population that would have to change residence, so that each lower level unit (e.g. neighborhoods) would have the same population distribution as the higher level unit (e.g. city) (Massey \& Denton, 1988). Different levels of segregation are possible in a similarly diverse city and vice versa. Others have therefore rather used segregation as moderator of heterogeneous diversity effects: diversity is particularly troublesome where accompanied by strong levels of segregation (e.g. Alesina \& Zhuravskaya, 2011; Schaeffer, 2014: Ch. 7). That said, the below-discussed flaws of diversity indices also apply to segregation indices.
} 


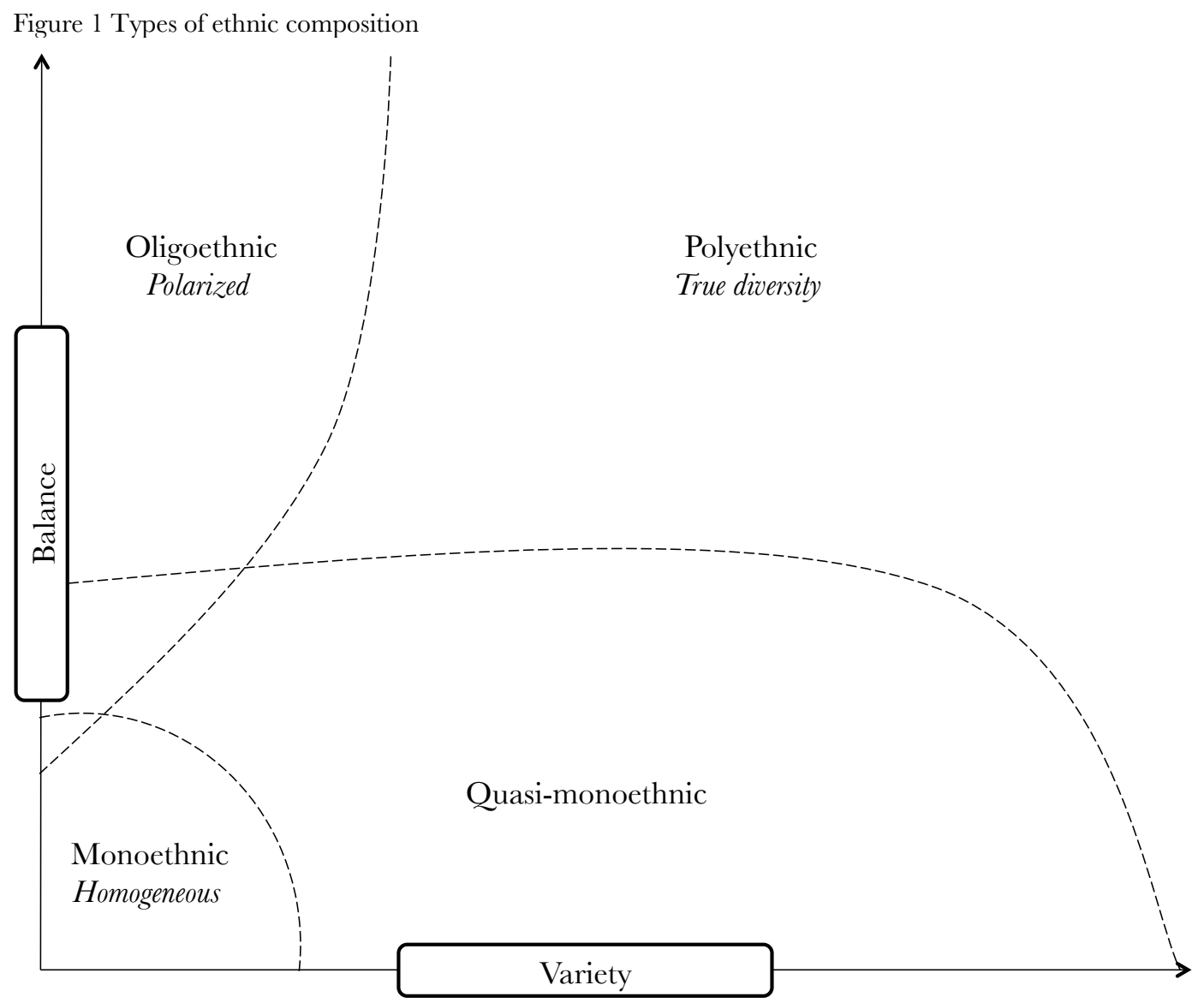


- Oligoethnic or polarized compositions are those in which few roughly equal-sized ethnic groups coexist. Polarized settings are therefore defined by low variety and strong balance. In the most polarized composition, two equal-sized groups face each other. According to Montalvo and Reynal-Querol (2005b), Guatemala ranges among the most polarized countries in the world with 55\% Ladinos and 42\% Maya.

- Polyethnic or truly diverse compositions are those with many more-or-less equal-sized groups, which results in both high variety and balance. This is the type of diversity that is best picked up by coventional diversity measures such as the HirschmanHerfindhal Index (HHI) (Hirschman, 1964). The 13 most diverse countries in the world according to this index are all located in sub-Saharan Africa, with Uganda leading the list (Alesina et al., 2003).

Note that the distinction between the four types of ethnic compositions is not analytical; no clear-cut criterion marks the distinction between a quasi-monoethnic and a polarized composition, which is why the boundaries of the four spaces in Figure 1 overlap. Nevertheless, this classification is important for clarifying the ideal-typical diversity situations that different theoretical approaches judge to be harmful or not for social cohesion and how these can be expressed in terms of balance and variety. While conventional diversity indices of the Herfindahl type accurately reflect the distinction between monoethnic and polyethnic populations, they do not capture the specificities of oligoethnic and quasi-monoethnic populations. To put it differently: because they collapse a theoretically two-dimensional space in a single number, conventional diversity indices may represent empirically and theoretically very different population compositions by the same diversity score. Proponents of group threat theory who regard polarized situations as most contentious have therefore proposed the so-called index of (ethnic) polarization as a more accurate indicator (Esteban \& Ray, 1994; Montalvo \& Reynal-Querol, 2005a; 2005b). But polarization indices, too, reduce a twodimensional theoretical space to a single number.

\subsection{Generalized (ethnic) entropy as solution to collinearity problems}

A potential solution would be to use in-group/out-group shares, diversity, and polarization simultaneously and compare their explanatory power. However, such a comparison is only possible under certain rather strict empirical conditions, as Schaeffer (2013a) has shown. Only if a sample of contextual units (such as work groups, cities or countries) entails quasimonoethnic, polarized, and truly diverse contexts, do these indices measure distinct 
properties. If however, as in most European cities or neighborhoods, the native population is always the large majority, and if the minority population is always highly diverse and not dominated by one or a few single groups, the measures are highly collinear and thus empirically indistinguishable. In particular, if a sample entails only quasi-monoethnic compositions, the unequal balance dimension dominates the commonly used diversity indices, which therefore fail to discriminate along the variety of groups dimension.

We propose generalized entropy as a solution to this problem. In physics, entropy indices measure a system's disorder - the variety of molecules' different discrete states and the (un-) equal probabilities (balance) of these states (Sethna, 2006, p. 81). If we replace the variety of discrete states by ethnic groups and the probabilities of these states by the groups' population shares, we can conceive of entropy as indices of ethnic disorder, i.e. diversity. ${ }^{3}$ The generalized entropy index (Page, 2010) is of particular interest, because it entails a scaling parameter $(\alpha)$ that weights balance against variety and hence allows giving more or less leverage to the latter dimension:

$$
\mathrm{E}_{k}^{\alpha}=\left(\sum_{i=1}^{k} s_{i}^{\alpha}\right)^{\frac{1}{1-\alpha}}
$$

where $\mathrm{E}$ is generalized entropy, $s_{i}$ denotes the share of ethnic group $i$, and $k$ the number of ethnic groups. $\alpha$, on the other hand, is the scaling parameter of interest that defines how much weight is given to variety and how much to balance when we compress or reduce those two aspects into a single number. For $\alpha=0$, the measure simply captures the number of ethnic groups; all weight is given to the variety dimension. Increasing $\alpha$ means to increase the weight we give to the balance dimension and to decrease the weight of variety. For $\alpha=\infty$, the entropy measure reduces to the inverse of the largest group's population share $\left(\frac{1}{s_{\text {largest }}}\right)$, and neglects variety altogether. Among all possible values for the scaling parameter a generally feasible one is $\alpha=2$, because here each group is weighted by its own population share, or in Page's words 'the measure weights proportions by their proportion' (Page, 2010: 70). To come full circle, the HHI is simply the inverse of generalized entropy (so that it varies between 0 and 1) with $\alpha=2$ and subtracted from unity (so that larger values denote more diversity).

\footnotetext{
${ }^{3}$ Some segregation measures are also based on entropy indices. They operationalize segregation as the degree to which a given level of entropy in a context is larger than the entropy of its constituent parts. For example, a city that is more diverse than its neighborhoods is segregated. The entropy-based segregation indices are recommended over others, because they fulfill most of the desired theoretical properties discussed in the literature (Reardon \& Firebaugh, 2002).
} 
Page (2010) suggests to compare the explanatory power of generalized entropy indices with different values for the scaling parameter $\alpha$ as a strategy to answer whether balance or variety is more important in accounting for diversity effects. At least for samples that are strongly dominated by quasi-monoethnic compositions, focusing on ethnic entropy is a superior alternative to comparing the HHI to the index of polarization, which are empirically indistinguishable under such circumstances. In particular, this strategy allows us to investigate whether the explanatory power of entropy indices increases with smaller values of $\alpha$, as predicted by theories that emphasize the variety of ethnic groups over which a population is spread. If in contrast cognitive biases (group threat and in-group favoritism) would be the main mechanism accounting for ethnic diversity effects, balance should be the crucial dimension and entropy indices should yield higher explanatory power at higher values of $\alpha$.

Alternatively, one might also consider to specify an interaction effect between a common diversity index and the number of (ethnic) groups present in the context; the same level of diversity could be more decisive for cohesion if the population were divided between more groups. But as we will explain in the next paragraph, such an attempt would still suffer from another fundamental flaw of common diversity measures, i.e. they have ambivalent implications, particularly for minority respondents. Next to using generalized entropy, another step is thus necessary to disentangle the theoretically important aspects of population heterogeneity in a coherent measurement framework: the decomposition of group-specific ingroup shares and out-group diversities/entropies.

\subsection{In-group share and relational out-group entropy, or why interaction effects will not do}

Conventional diversity and entropy indices share a fundamental problem: they measure a macro state that has ambiguous implications on the micro level in two regards. First, diversity indices have frequently been criticized for their color blindness and their failure to take into account that the same level of diversity may have different implications for majority and minority members. In most immigration countries, very high levels of ethnic homogeneity only occur in areas dominated by natives, where there are few persons of immigrant origin of any ethnic group. Thus for natives, in-group size and diversity are negatively correlated - and often so highly that it becomes practically impossible to distinguish the two in empirical analyses using traditional diversity indices, such as the HHI (in our sample: $r=-0.96$, $\mathrm{p}<0.000$ ). Accordingly, for natives, out-group size and thus presumably out-group threat increases with diversity. But the opposite holds for minorities, i.e. out-group size tends to be 
inversely related to diversity, as in the limit case of a lone person of immigrant origin living in a setting completely dominated by natives.

This problem can be handled by introducing interaction effects, or by conducting separate analyses for minority and majority samples. Both strategies have been used in those, relatively few, studies that do not disregard members of minority groups altogether. Some of these studies report a weaker (Putnam, 2007; Stolle et al., 2008; similarly an earlier analysis of the data used in this paper, see Koopmans and Schaeffer, 2016), others no significant relation between diversity and social cohesion measures among minority members (Bakker \& Dekker, 2012; Fieldhouse \& Cutts, 2010). But while such analyses acknowledge the possibility of effect heterogeneity between majority and minority respondents, they still disregard another ambiguity of diversity indices.

Second, namely, diversity indices measure competing properties for minorities. More diversity will most of the time mean more in-group members for minorities (particularly in immigration contexts), because where there are more persons of immigrant origin, there will as a general tendency also be more members of each single immigrant group. This is not necessarily the case, but frequently enough for the HHI to show a modest positive correlation with the in-group shares of persons of immigrant origin (in our sample: $r=0.29, p<0.000$ ). But at the same time, it correlates positively with the relative share and absolute number of other minority groups (in our sample: $\mathrm{r}=0.92, \mathrm{p}<0.000$, and $\mathrm{r}=0.70, \mathrm{p}<0.000$ respectively). That is, diversity indices measure two competing properties among minorities. On the one hand, they measure the concentration of other minority groups and their diversity, which should drive down trust. But on the other hand, they also measure in-group share, which should drive up trust. This means that the estimated diversity effects among minorities reported in the literature carry an ambivalent interpretation. Probably for this reason, they have been found to be weaker in strength or statistically insignificant in previous work. As a result, these measures are inadequate for testing the predictions of in-group favoritism and group threat accounts of diversity effects even when we consider interaction effects or carry out separate analyses for minorities and the majority. This also demonstrates that the above-mentioned possibility to introduce an interaction effect between a common diversity index and the number of (ethnic) groups present in the context might help to shed light on the relevance of balance versus variety, but would still suffer from ambiguity flaws.

Instead of any such work-arounds, a coherent measurement framework that solves all of these problems is needed. We suggest decomposing in-group share and diversity into two separate statistics. Combining this idea with our initial proposal to use generalized entropy, 
this can be easily achieved by decomposing ethnic diversity into the group-specific in-group population shares and (ethnic) out-group entropies:

$$
\begin{aligned}
& \text { In-Group Share }=\frac{n_{i}}{N_{k}} \\
& \operatorname{RE}_{k}^{\alpha}=\left(\sum_{i=1}^{g} \frac{n_{j}^{\alpha}}{N_{g}}\right)^{\frac{1}{1-\alpha}}
\end{aligned}
$$

where RE is generalized relational (out-group) entropy, $n$ is the number of members of ingroup $i$ or out-group $j$ and $N$ is the overall population. $k$ is the overall number of groups, including the in-group, while $g$ is the number of out-groups. We call this index relational, because our measure takes the relative position of each group into account, resulting in two times (in-group share and diversity of the others) as many diversity scores as there are groups in a given context - in addition to the possibility to vary $\alpha$. This stands in stark contrast to the existing global indices that estimate a single score for a given context. It means that particular diversity values not only need to be matched to particular contexts, but also to particular groups within particular contexts. Our proposed solution recognizes that the ethnic composition of, say, Berlin is different when seen from the perspective of a person of Turkish as compared to that of one of Irish origin. For the former, diversity may be counterbalanced by the fact that persons of Turkish origin constitute in some neighborhoods a sizeable minority, whereas, given the small size of the Irish population in Berlin, those of Irish origin never live in neighborhoods where their ethnic in-group forms a significant part of the population. We believe with Coleman (1990) that this is a theoretically desirable property. Good macro sociology should not only investigate macro relations, but also specify how macro-demographic structures impact upon individuals and this entails that similar macro structures might have different implications for different individuals.

\subsection{Relational diversity and competing theories of diversity effects: bringing it all together}

Our new measures disentangle the aspects of population heterogeneity emphasized by the competing theoretical traditions, as we summarize in Table 1. Each of the discussed theories predicts the in-group share to be positively related to social cohesion. Most obviously, this is the case for theories of in-group favoritism, which expect trust and cooperation to be highest, the more public goods accrue to in-group members. Because in-group and total out-group size are inversely related, detrimental effects on social cohesion of perceived out-group threat should also be more limited the larger the in-group. And finally, since a larger in-group size 
increases the number of people with whom one shares a language, norms, and preferences, and with whom one maintains close network links, in-group size should also be associated with greater social cohesion according to the other theoretical perspectives.

Table 1 Expected relations between relational diversity and social cohesion

\begin{tabular}{|c|c|c|c|}
\hline & \multirow{2}{*}{$\begin{array}{l}\text { In-group share } \\
\text { beta coefficient }\end{array}$} & \multicolumn{2}{|c|}{ Relational (out-group) entropy } \\
\hline & & beta coefficient & alpha \\
\hline In-group favoritism & + & 0 & \\
\hline Orthodox out-group threat & + & 0 & \\
\hline Polarization threat & + & + & High \\
\hline $\begin{array}{l}\text { Coordination problems, prefer- } \\
\text { ence diversity, network closure }\end{array}$ & + & - & Low \\
\hline
\end{tabular}

By contrast, our relational entropy measures allow for distinctions between the theoretical perspectives. For in-group favoritism and conventional group threat theories, relational outgroup entropy should simply not matter. As we already laid out in the theory section, only relative comparisons between in-group and out-group members matter, but not the composition of the out-group. But for those proponents of group threat theory that see polarization as the most contentious situation, a unified out-group is seen as more threatening than a similarly sized out-group population composed of many small groups. Accordingly, the lower the degree of diversity (entropy) among out-groups, i.e., the more the out-group is dominated by one single group, the more should we should expect negative impacts on social cohesion. That is, following the polarization theorists, we should expect a positive coefficient of relational (out-group) entropy. Moreover, relational (out-group) entropy should be a particularly precise predictor at high values of $\alpha$, which emphasize the degree of concentration within the out-group population. If on the other hand coordination problems, diverse preferences, or network density are the main explanations for lower social cohesion, the fractionalization of out-group members is a crucial factor. Hence these theories would also predict out-group entropy to matter, but in such a way that higher levels of out-group diversity reduce social cohesion, which implies a negative coefficient. On top of that, according to these theories relational out-group entropy should be a precise predictor of declining cohesion at lower values of alpha, which emphasize variety rather than balance. 


\section{Data and Methods}

The analysis relies on the German subset of the Ethnic Diversity and Collective Action Survey (EDCAS), which was conducted between October 2009 and April 2010 (Schaeffer et al., 2011). The German part of the survey consists of 7,500 standardized telephone interviews with people who are at least 18 years of age. The survey has a 26 per cent oversample of persons of immigrant origin, here defined as either being born abroad or having at least one parent born abroad. There is an additional 14 per cent oversample of persons of Turkish origin. In order to prevent unfeasible screening costs these latter respondents were not sampled via random digit dialing but via their last names from telephone directories. These participants also had the possibility to conduct the interview either in German or Turkish. 55 urban and rural Kreise stratify the sample. Kreise are administrative units with an average population of about 190.000 inhabitants. In each region, 100 respondents were interviewed, except in five of the largest German cities where we conducted 500 interviews.

The second level of this analysis, the city or region, is much larger than the respondents' personally experienced neighborhood. This raises the question, whether statistics about cityand regional-level diversity are actually perceived by the respondents. Figure A1 in the appendix shows that there is a remarkably precise relation between respondents' average perceptions of local minority concentration ${ }^{4}$ as compared to the actual percentage of persons of immigrant origin in their city or rural district $(\mathrm{r}=0.94 ; \mathrm{p}<0.000)$. Individual perceptions are quite scattered, but on average, city and district-level diversity seems to be a fairly accurate proxy of people's every-day experiences.

\subsection{Variables}

As dependent variables, we analyze three indicators of social cohesion that are of particular interest, as well as an overall neighborhood cohesion scale. The first, trust in neighbors, is identical to the measure Putnam (2007) used.

Please indicate on a scale from 0 to 10, how much you trust the people in your neighborhood.

Our second measure, collective efficacy, was originally developed by Sampson, Morenoff and Earls (1999) and is designed to measure a community's capacity to collectively solve

\footnotetext{
${ }^{4}$ The question posed to respondents was: 'How high do you estimate the percentage of people of nonGerman origin in your neighborhood to be? With non-German origin we mean people who were not born in Germany or of whom at least one parent was not born in Germany. Please give a percentage between 0 and 100 .'
} 
neighborhood problems, such as waste lying about or street muggings and harassment. We measured collective efficacy with two items that are influenced by Friedrichs and Oberwittler (2007), who adapted the concept to suit the German context.

In neighborhoods there are different problems. Let me give you some examples:

On a public green space lies bulky waste. On a scale from zero to ten, how likely is it that people from your neighborhood would jointly try to find a solution?

In a dark alley several people have been mugged. On a scale from zero to ten, how likely is it that people from your neighborhood would jointly try to find a solution?

The third indicator, reported social problems in the neighborhood, serves as an indicator of under-provision of neighborhood public goods. We use a scale of two items, which refer to the same public goods as those used for measuring collective efficacy. We assume that disorderly waste disposal and unsafety are indicative of a failure of informal social control and cooperative norms in the neighborhood.

How often do the following problems occur in your neighborhood? Never, rarely, sometimes, often or very often?:

Waste lying about?

Harassment or verbal abuse?

In comparison to collective efficacy, disorder focuses on the experience of neighborhood problems rather than on a community's capacity to jointly solve these problems. These theoretical differences also hold empirically. A rotated explorative principle component factor analysis of all four items suggests a two-factor solution, with both factors having an eigenvalue above 1 . The collective efficacy items load on the first item with factor loadings above 0.88 and the disorder items load on the second factor with factor loadings above 0.83 . We use simple average scores to construct the two scales. Reported neighborhood problems has a Cronbach's alpha of 0.6 and collective efficacy of 0.76 . For the sake of consistency and easier comparison, we reversed the neighborhood problem scale so that high values indicate a lack of experienced social problems as an indicator of neighborhood social cohesion.

In addition to these separate indicators, we built a neighborhood cohesion scale based on all the above-mentioned items that consists of the predicted factor scores after an exploratory maximum likelihood factor analysis. The factor scores vary between -0.55 and 0.79 . 
To measure the degree of ethnic diversity of the cities and regions in which the respondents live, we use data from the Federal Office for Migration and Refugees' central register of foreign nationals, which is the most reliable source of information on the foreign population in Germany. The population shares of people from all 193 fully recognized nations are available. Ethnic categories are thus defined by nationality, which fits the way ethnicity is generally conceived of in Germany (Schaeffer, 2013b). However, using nationality to distinguish ethnic categories has the disadvantage that people of immigrant origin who have acquired German citizenship are treated as German natives, implying that we underestimate diversity. Therefore, we conducted additional analyses with inflated indices that do not underestimate the overall share of persons of immigrant origin (Koopmans \& Veit, 2014a; Schaeffer, 2013a). The results of these analyses do not lead to any alternative conclusions, so we here only report results based on nationality.

We estimate a series of different relational entropy measures by varying the scaling factor $\alpha$ between 3 and 0.1 in 0.1 sized steps, i.e., 30 indices overall. We choose the rather low value of 3 as a starting point, because already for a value of 2 the measure gives little weight to the variety dimension. The 30 indices of course correlate strongly with one another. For this reason, rather than testing the indices against each other in one model, we estimate separate models and compare the precision of our estimates in terms of the coefficients' t-statistics. To measure in-group size, we attribute to each respondent the local population share of his or her ethnic group. This implies that we calculate up to 194 (193 immigrant ethnic groups plus natives) in-group shares, as well as up to 194 distinct relational entropy measures (times 30 values for $\alpha$ ) for each of the 55 contextual units.

Importantly, the effects of in-group size and relational out-group entropy are empirically distinguishable because the two measures have low inter-correlations among both natives $(.24$ at $\alpha=2$ ) and persons of immigrant origin (.02). Only in the combined sample do the variables correlate highly (.82). This is because out-group diversity tends to be low for persons of immigrant origin (because of the strong dominance of natives among out-groups) and high for natives (because of the generally high variety of immigrant groups across Germany) while simultaneously in-group size is low for persons of immigrant origin and high for natives. We deal with this problem by introducing interaction effects for the native and immigrant origin samples.

The cross-sectional design of our study does not allow us to make strong causal claims, which is why we refer to the estimated coefficients of the independent variables as predictors rather than effects. Nevertheless, by controlling for important and potentially confounding 
factors, we try to come as close to a causal estimate as possible. The additional control variables are the number of years someone has lived in the neighborhood, home ownership, education, gender, dummies indicating the religious confession, being married, and age. On the context level, the analyses control for East/West-German differences, the local unemployment rate, and the population per square kilometer. In additional robustness analysis (see Table A2 in the appendix), we also control for the total size of the local foreign population, because, all other things being equal, there is a greater likelihood that many different ethnic groups are represented in a particular context if the absolute number of immigrants is large. Moreover, we also include measures of inter-ethnic contact (interacted by immigrant origin) in these robustness analyses, because the decomposed terms of our diversity measure might be differently related to the opportunity for inter-ethnic contact, which is often discussed as an important moderating mechanism of diversity effects (Stolle et al., 2008; Koopmans \& Veit, 2014b). In particular we operationalize inter-ethnic contact by the number of inter-ethnic neighborhood acquaintances ${ }^{5}$ and the frequency of inter-ethnic neighborhood encounters in bars and restaurants, public places and parks. ${ }^{6}$ However, as appendix Table A2 shows, our results remain virtually unchanged while adjusting for these control variables. The descriptive statistics of all dependent and independent variables are shown in Table 2.

\subsection{Modeling strategy}

We estimate linear regression models that pool natives and respondents of immigrant origin, but include interaction effects for the relevant diversity indicators. Since the data is clustered in 55 cities and rural regions and the analyses include context-level variables, a multi-level modeling strategy is needed. We estimate models with cluster-robust standard errors. These have the advantage that the standard errors of parameters of context-level regressors are not underestimated (Angrist \& Pischke, 2009: 308-323). Moreover, they

\footnotetext{
${ }^{5}$ The survey questions was: 'Now I am going to ask you questions about your acquaintances in the neighborhood. With acquaintances I mean people who you know by name and with whom you have a chat frequently, if you come across. How many of your acquaintances from the neighborhood are of immigrant origin [are of German descent]?'. Answers could range from none, one, two to five, six to ten and ten or more acquaintances. Following Zheng et al.'s (2006) suggestion, we took the middle value of each range as the respondents' number of acquaintances and set the value for the category of ten or more to eleven.

${ }^{6}$ The survey questions was 'How often do you encounter people of immigrant origin [of German descent] when you visit bars, restaurants, tearooms or coffee shops in your neighborhood?' and 'How often do you encounter people of immigrant origin [of German descent] when you visit public parks, squares, and playgrounds in your neighborhood?'. Answers could range between 'never' (0), 'seldom' (1), 'sometimes' (2), 'often' (3) and 'very often' (4). The two items correlated strongly and were merged into a composite indicator of the frequency of casual interethnic encounters in the neighborhood $(\mathrm{a}=.84)$.
} 
assume 'no particular kind of within-cluster correlation nor a particular form of heteroscedasticity' (Wooldridge, 2003: 134), meaning that they allow for any kind of upper and lower-level heteroscedasticity. Random intercept models, an alternative estimation strategy, assume homoscedastic errors on both the individual and contextual level (e.g. RabeHesketh \& Skrondal, 2008). For our analyses, this is an unrealistic assumption given that some contextual units are highly dense and socio-culturally heterogeneous cities like Berlin or Hamburg, while others are sparsely populated, homogeneous rural areas like Oberallgäu. Yet, results of estimations that rely on random intercept models yield similar conclusions.

Table 2 Descriptive statistics

\begin{tabular}{|c|c|c|c|c|c|c|c|c|}
\hline & \multicolumn{4}{|c|}{ Natives } & \multicolumn{4}{|c|}{ Persons of immigrant origin } \\
\hline & Mean/ $\pi$ & $\mathrm{SD}$ & Min & Max & Mean $/ \pi$ & $\mathrm{SD}$ & Min & $\operatorname{Max}$ \\
\hline & \multicolumn{8}{|c|}{ Dependent Variables } \\
\hline Trust in neighbors & 7.18 & 2.29 & 0 & 10 & 6.22 & 2.72 & 0 & 10 \\
\hline Collective efficacy & 6.33 & 2.54 & 0 & 10 & 6.01 & 2.61 & 0 & 10 \\
\hline Lack of social problems & 3.25 & 0.75 & 0 & 4 & 3.23 & 0.85 & 0 & 4 \\
\hline \multirow[t]{2}{*}{ Neighborhood cohesion scale } & 0.09 & 0.95 & -3.45 & 1.66 & -0.12 & 1.05 & -3.97 & 1.66 \\
\hline & \multicolumn{8}{|c|}{ Individual-level variables } \\
\hline Age (in 10 years) & 5.34 & 1.69 & 1.80 & 9.70 & 4.14 & 1.43 & 1.80 & 9.70 \\
\hline Education, reference: Low & 0.04 & & & & 0.15 & & & \\
\hline Medium education & 0.62 & & & & 0.60 & & & \\
\hline High education & 0.34 & & & & 0.25 & & & \\
\hline Employed & 0.58 & & & & 0.65 & & & \\
\hline $\begin{array}{l}\text { Residence in the neighborhood } \\
\text { (in } 10 \text { years) }\end{array}$ & 2.33 & 1.80 & 0 & 9.00 & 1.32 & 1.04 & 0 & 7.50 \\
\hline Home owner & 0.53 & & & & 0.33 & & & \\
\hline Female & 0.55 & & & & 0.52 & & & \\
\hline Married & 0.50 & & & & 0.56 & & & \\
\hline Religion, reference: Atheist & 0.46 & & & & 0.33 & & & \\
\hline Protestant & 0.26 & & & & 0.06 & & & \\
\hline Catholic & 0.22 & & & & 0.15 & & & \\
\hline Muslim & 0.00 & & & & 0.38 & & & \\
\hline Other & 0.05 & & & & 0.09 & & & \\
\hline East Germany & 0.18 & & & & 0.07 & & & \\
\hline Inter-ethnic nbh acquaintances & 2.42 & 3.16 & 0 & 11 & 7.84 & 3.70 & 0 & 11 \\
\hline \multirow[t]{2}{*}{ Inter-ethnic nbh encounters } & 1.74 & 1.20 & 0 & 4 & 2.61 & 1.20 & 0 & 4 \\
\hline & \multicolumn{8}{|c|}{ Contextual-level variables } \\
\hline Local unemployment rate & 0.09 & 0.03 & 0.03 & 0.15 & 0.08 & 0.03 & 0.03 & 0.15 \\
\hline Aggregate level & 0.08 & 0.04 & 0.03 & 0.15 & 0.08 & 0.03 & 0.04 & 0.15 \\
\hline Population density & 1.42 & 1.34 & 0.04 & 4.27 & 1.67 & 1.37 & 0.04 & 4.27 \\
\hline Aggregate level & 0.76 & 0.96 & 0.04 & 3.85 & 1.15 & 1.10 & 0.08 & 4.27 \\
\hline $\begin{array}{l}\text { Abs. number of foreign nationals } \\
\text { (in 1000) }\end{array}$ & 88.65 & 128.58 & 1.08 & 448.39 & 106.99 & 131.64 & 1.08 & 448.39 \\
\hline Aggregate level & 37.15 & 93.24 & 1.08 & 448.39 & 47.27 & 67.96 & 4.72 & 293.57 \\
\hline Relational (out-group) Entropy ${ }^{0.5}$ & 59.65 & 12.10 & 37.01 & 81.88 & 16.97 & 7.19 & 3.43 & 30.11 \\
\hline Aggregate level & 58.79 & 11.22 & 39.73 & 77.79 & 14.47 & 6.45 & 5.67 & 29.37 \\
\hline In-group share & 0.84 & 0.09 & 0.63 & 0.98 & 0.02 & 0.03 & 0.00 & 0.11 \\
\hline Aggregate level & 0.88 & 0.10 & 0.63 & 0.98 & 0.02 & 0.03 & 0.00 & 0.10 \\
\hline
\end{tabular}

Unfortunately, only $82 \%$ of the native German and $77 \%$ of the respondents of immigrant origin answered all questions. This is particularly due to missing values on religious and 
educational background. We therefore estimate the models with thirty multivariate imputations for missing values - herewith we follow the suggestion of Graham et al. (2007). As proposed by Enders (2010), the imputation model consisted of all variables used in the analyses. The imputation procedure also includes respondents who discontinued the telephone interview, because these were part of the original sampling plan and should thus not be excluded.

\section{Results}

In order to compare entropy at 30 different levels of the scaling parameter, we estimated altogether 120 regressions including the full set of contextual and individual level controls, for each of our four dependent variables. Because we cannot display the full results of so many regression models, we first determine at which level of the $\alpha$ parameter our measure of relational out-group entropy is most precise in predicting neighborhood cohesion. Figure 2 shows the results in terms of the t-statistics of the marginal effects of the relational out-group entropy measures for natives and immigrants separately.

The t-statistics indicate that the variety component of diversity drives responses to diversity for both persons of immigrant origin and natives. As $\alpha$ decreases, so that the relational out-group entropy measure gives more emphasis to the variety of groups rather than to the balance of their population shares, precision increases. For persons of immigrant origin, out-group entropy is a significant predictor of all dependent variables except the lack of social problems, where it only reaches marginal (two-tailed) levels of significance. For the other indicators of neighborhood cohesion it is a significant predictor for the whole investigated range of $\alpha$, but reaches its strongest predictive power at $\alpha \approx 0.5$, i.e. a diversity index that gives considerably more weight to the variety dimension than the classical HHI. For even smaller $\alpha$ values, at which the index merely reflects the number of groups without considering their population shares, the precision diminishes again and eventually loses significance. 
Figure 2 Precision of ethnic entropy with varying $\alpha$

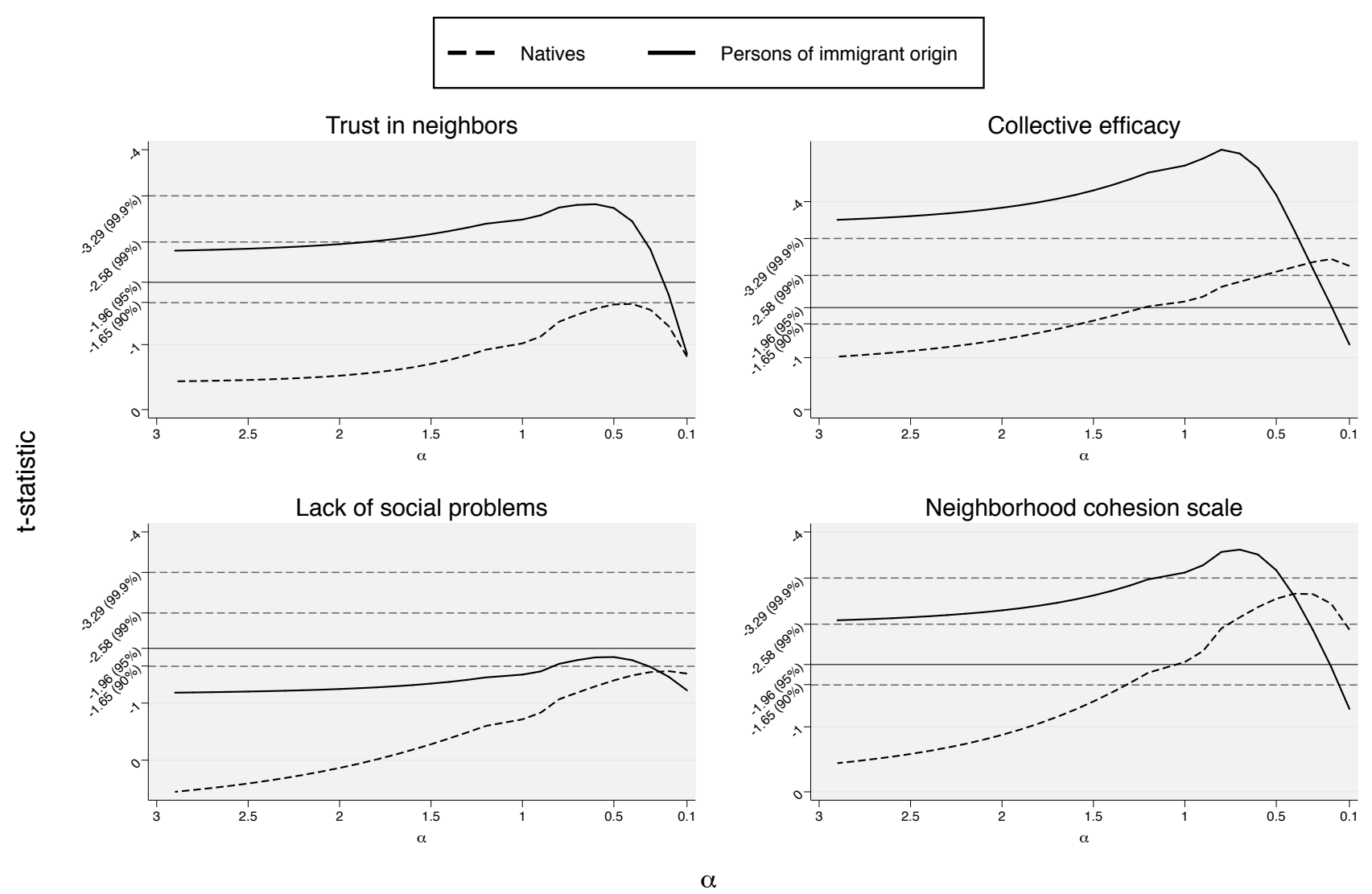


For natives, we see a very similar pattern of increasing precision as $\alpha$ declines, and outgroup entropy becomes a significant predictor of collective efficacy and the overall neighborhood cohesion scale at $\alpha$ levels of roughly 1 and lower, where the measure heavily weighs the number rather than the relative sizes of out-groups. For trust in neighbours and reported social problems the tendency is similar, but the entropy measures only scratch the border of marginal (two-tailed) significance. Contrary to any version of group threat theory, we thus find that, given a certain level of total out-group size, the variety of different ethnic out-groups matters negatively for both natives and respondents of immigrant origin. Another noteworthy implication of the results is that with a relativized conventional measure of diversity such as the HHI, which is comparable to the $\alpha=2$ level in the figure, we would not have found any significant relational out-group diversity effect for natives, and would have underestimated relational out-group diversity effects for persons of immigrant origin. Thus, entropy measures not only allow us to differentiate between theoretical mechanisms that have been proposed for diversity effects, but also to detect diversity effects where we would otherwise have concluded that there are none.

We now turn our attention to the direction of the association, and to the role of in-group size. To this end we present in Table 3 regression results and marginal effects by immigrant origin using relational entropy at $\alpha=0.5$, which as Figure 2 showed is the level of $\alpha$ at which it predicts our social cohesion measures best. We do not display the results for the control variables, but the full regression tables can be found in the appendix (Table A1). Results for in-group size in Table 3 are similar to those using entropy at other $\alpha$ levels (results available upon request).

According to the marginal effects shown in the lower panel of Table 3, in-group share is a strong and significant predictor of neighborhood cohesion among native respondents, but less so among persons of immigrant origin. While the marginal effects for majority and minority respondents are quite similar in size - with the exception of trust in neighbors - the standard errors for persons of immigrant origin are too large to reject the null. Accordingly, the interaction effects do not suggest that in-group share plays a significantly different role across the groups either. Among natives, a standard deviation increase of the in-group share is associated with an increase of neighborhood cohesion by roughly half a standard deviation in neighborhood cohesion. Overall, this supports the prediction, which all theoretical perspectives on diversity effects share, that in-group size matters. 
Table 3 Relational diversity as predictor of neighborhood cohesion across 55 German cities and regions

\begin{tabular}{|c|c|c|c|c|}
\hline & $\begin{array}{l}\text { Trust in } \\
\text { neighbors }\end{array}$ & $\begin{array}{l}\text { Collective } \\
\text { efficacy }\end{array}$ & $\begin{array}{c}\text { Lack of } \\
\text { social problems }\end{array}$ & $\begin{array}{l}\text { Neighborhood } \\
\text { cohesion scale }\end{array}$ \\
\hline \multicolumn{5}{|c|}{ OLS Regression coefficients } \\
\hline \multirow[t]{2}{*}{ In-group share } & $0.451^{* * *}$ & $0.517^{* * *}$ & $0.483^{* *}$ & $0.644^{* * *}$ \\
\hline & $(0.072)$ & $(0.087)$ & $(0.177)$ & $(0.115)$ \\
\hline \multirow[t]{2}{*}{ *Immigrant origin } & -0.428 & -0.016 & -0.252 & -0.240 \\
\hline & $(0.276)$ & $(0.300)$ & $(0.453)$ & $(0.337)$ \\
\hline \multirow[t]{2}{*}{ Relational (out-group) Entropy ${ }^{0.5}$} & -0.042 & $-0.102^{* *}$ & -0.076 & $-0.103^{* *}$ \\
\hline & $(0.026)$ & $(0.037)$ & $(0.051)$ & $(0.034)$ \\
\hline \multirow[t]{2}{*}{ *Immigrant origin } & $-0.174^{*}$ & $-0.202^{*}$ & -0.171 & $-0.245^{*}$ \\
\hline & $(0.074)$ & $(0.088)$ & $(0.124)$ & $(0.108)$ \\
\hline \multicolumn{5}{|c|}{ Marginal effects } \\
\hline \multirow{3}{*}{ In-group share } & & & & \\
\hline & $0.451^{* * *}$ & $0.517^{* * *}$ & $0.483^{* *}$ & $0.644^{* * *}$ \\
\hline & $(0.072)$ & $(0.087)$ & $(0.177)$ & $(0.115)$ \\
\hline \multirow[t]{2}{*}{ Relational (out-group) Entropy ${ }^{0.5}$} & -0.042 & $-0.102^{* *}$ & -0.076 & $-0.103^{* *}$ \\
\hline & $(0.026)$ & $(0.037)$ & $(0.051)$ & $(0.034)$ \\
\hline \multicolumn{5}{|c|}{ Persons of immigrant origin } \\
\hline \multirow[t]{2}{*}{ In-group share } & 0.023 & 0.501 & 0.232 & 0.404 \\
\hline & $(0.276)$ & $(0.283)$ & $(0.426)$ & $(0.310)$ \\
\hline \multirow[t]{2}{*}{ Relational (out-group) Entropy ${ }^{0.5}$} & $-0.216^{* *}$ & $-0.304^{* *}$ & -0.247 & $-0.348^{* *}$ \\
\hline & $(0.074)$ & $(0.088)$ & $(0.141)$ & $(0.116)$ \\
\hline Control variables & Yes & Yes & Yes & Yes \\
\hline $\mathrm{N}$ & 7888 & 7888 & 7888 & 7888 \\
\hline
\end{tabular}

A comparison among theories is however possible on the basis of the association between neighborhood cohesion and relational out-group entropy. The marginal effects of Table 3 show that among persons of immigrant origin the diversity of others is strongly negatively related to neighborhood cohesion, with a standard deviation increase predicting a reduction of between $22 \%$ (trust in neighbors) to $35 \%$ (neighborhood cohesion scale) of a standard deviation in neighborhood cohesion. This strong negative relation flatly contradicts the polarization variant of group threat theory, which predicts a positive relationship between outgroup diversity and cohesion, because a homogeneous out-group is supposedly more threatening than a fractionalized one. The negative relationship between out-group entropy and cohesion can neither be accounted for by orthodox group threat theory, nor by theories of in-group favoritism, which both only consider in-group/out-group balances and do not predict the degree of out-group diversity to matter at all. Among natives the results are less outspoken than among persons of immigrant origin, but they nevertheless consistently have a negative sign, and are statistically significantly predictors of collective effcicacy and the overall neighborhood cohesion scale. Among members of the native ethnic majority, a standard deviation increase in out-group diversity is associated with a $10 \%$ decline in neighborhood cohesion. 


\section{Conclusion}

Diversity consists of two defining properties: variety and balance. But in most settings, the well-established diversity indices do not properly account for the crucial variety dimension of diversity. This reflects the relative theoretical neglect of cultural and network explanations and the dominant view that negative ethnic diversity effects are rooted in feelings of outgroup threat and in-group favoritism. In this paper, we have proposed two innovative ways to de-compose diversity indices in order to compare the predictions of competing explanations of why ethnic diversity matters. First, we distinguish in-group share from the diversity of ethnic out-groups. Second, we show how generalized entropy measures can be used to test which of diversity's two basic dimensions matters most: the variety of groups, or the balance of their population shares. This de-composition allows for straightforward tests of competing theories. In-group favoritism and group threat theories emphasize the relative sizes of ingroup and out-groups (i.e., balance aspects of diversity), whereas theories about coordination problems, preference diversity, and network closure predict trust and cooperation problems to increase with the number of different groups (i.e., the variety aspect of diversity). An additional advantage of our approach is that it can be applied to samples of contextual units that are strongly dominated by what we have called 'quasi-monoethnic' settings, i.e. contextual units that are dominated by one large majority. In such contexts, which are the rule rather than the exception in most immigration countries, conventional diversity and polarization indices are indistinguishable from each other as well as from the mere percentage shares of natives or immigrants. Lacking a measurement instrument that is sensitive to theoretically relevant features of ethnic composition, the findings of research on the impact of immigration on social cohesion have, in spite of the large number of studies that have been conducted, remained theoretically inconclusive. We view our de-compositional and relational approach to diversity as a promising way to arrive at theoretically more meaningful conclusions.

The results of our application of these ideas in an analysis of social cohesion across 55 German localities speak against the majority of the sociological and political science literatures, which treat in-group favoritism and feelings of group threat as the key explanatory mechanisms accounting for negative ethnic diversity effects. Our results most clearly contradict the polarization variant of group threat theory, which had led us to expect the greatest reductions in trust, collective efficacy and other measures of neighborhood cohesion where there is a large and homogeneous outgroup. In direct contrast to this prediction, we find that outgroup entropy become a better predictor of eroded neighborhood cohesion the more 
we emphasize fractionalization rather than balance. The patterns that we find also speak against in-group favoritism and orthodox group threat theory as exclusive explanations, since for these theories only the relative size of the in-group matters and the diversity of out-groups should have been irrelevant. Only theories about increased collective choice obstacles, reduced social control, and coordination problems in settings with a large variety of groups can account both for out-group diversity as a negative predictor of neighborhood cohesion, and for the fact that out-group diversity is a more potent predictor if we use values of $\alpha$ that emphasize the variety rather than the balance component of diversity.

Had we used conventional measures of diversity, we would not have been able to test these theories against one another. Our results show that the in-group share is significantly and positively associated with higher levels of trust, efficacy and overall neighborhood cohesion, but this a finding that all the theoretical perspectives predict and that therefore does not differentiate amongst them. The same is obviously true for the inverse of the in-group share, i.e. the overall outgroup share, which has for instance been used in many studies of trust and cohesion among native samples in the form of the immigrant population share. Using traditional diversity indices would not have helped us. First, because in most immigration settings they are highly collinear with the percentage of immigrants and thereby with the ingroup share for natives and with the outgroup share for immigrants. Second, because they collapse the variety and balance dimensions of diversity into a single number and thereby preclude a differential test of theories.

By showing how more differentiated and relational diversity measures allow comparative tests of theories of diversity effects that are not possible with conventional diversity measures we hope to inspire other researchers to move away, where possible, from conventional diversity measures. We should take seriously that, from a theoretical perspective, diversity is neither a one-dimensional phenomenon, nor is it plausible to expect that the same aggregate ethnic composition affects all members of a population in the same way, regardless of their own group membership. Diversity is about balance and variety, and different theoretical perspectives emphasize the one or the other of these dimensions. All available theoretical approaches moreover imply that in-group size should matter. But nevertheless, for any particular context, conventional diversity indices attribute the same diversity value to a member of a dominant group member who lives surrounded by co-ethnics, as to a member of a tiny minority, who has no in-group members around him. Tying our measurement instruments more closely to relevant theoretical approaches may help move ahead a research field that is currently characterized more by repetition than by theoretical advancement. 


\section{References}

Alesina, A., Devleeschauwer, A., Easterly, W., Kurlat, S., \& Wacziarg, R. (2003). Fractionalization. Journal of Economic Growth, 8(2), 155-194.

Alesina, A., \& Zhuravskaya, E. (2011). Segregation and the Quality of Government in a CrossSection of Countries. American Economic Review, 101(5), 1872-1911.

Angrist, J. D., \& Pischke, J.-S. (2009). Mostly Harmless Econometrics: An Empiricist's Companion. Princeton: Princeton University Press.

Bakker, L., \& Dekker, K. (2012). Social Trust in Urban Neighbourhoods: The Effect of Relative Ethnic Group Position. Urban Studies, 49(10), 2031-2047.

Bécares, L., Stafford, M., Laurence, J., \& Nazroo, J. (2011). Composition, Concentration and Deprivation. Urban Studies, 48(13), 2771-2787.

Blalock, H. M. (1967). Toward a Theory of Minority-Group Relations. New York: Wiley.

Brown, R. (2000). Social Identity Theory: Past Achievements, Current Problems and Future Challenges. European Journal of Social Psychology, 30(6), 745-778.

Coleman, J. S. (1990). Foundations of Social Theory. Cambridge: Harvard University Press.

Desmet, K., Ortuno-Ortín, I., \& Wacziarg, R. (2012). The Political Economy of Linguistic Cleavages. Journal of Development Economics, 97(2), 322-338.

Dincer, O. C. (2011). Ethnic Diversity and Trust. Contemporary Economic Policy, 29(2), 284-293.

Dinesen, P. T., \& Sønderskov, K. M. (forthcoming). Ethnic Diversity and Social Trust: Evidence from the Micro-Context. American Sociological Review.

Enders, C. K. (2010). Applied Missing Data Analysis. New York: Guilford Press.

Esteban, J.-M., \& Ray, D. (1994). On the Measurement of Polarization. Econometrica, 62(4), 819851.

Fieldhouse, E., \& Cutts, D. (2010). Does Diversity Damage Social Capital? A Comparative Study of Neighbourhood Diversity and Social Capital in the US and Britain. Canadian Journal of Political Science/Revue Canadienne de Science Politique, 43(02), 289-318.

Friedrichs, J., \& Oberwittler, D. (2007). Soziales Kapital in Wohngebieten. In A. Franzen \& M. Freitag (Eds.), Sozialkapital: Grundlagen und Anwendungen (pp. 450 - 486). Wiesbaden: Kölner Zeitschrift für Soziologie und Sozialpsychologie (Sonderheft No. 47).

Gould, R. V. (2003). Collision of Wills: How Ambiguity about Social Rank Breeds Conflict. Chicago: University Of Chicago Press.

Graham, J. W., Olchowski, A. E., \& Gilreath, T. D. (2007). How Many Imputations are Really Needed? Some Practical Clarifications of Multiple Imputation Theory. Prevention Science, 8(3), 206-213.

Habyarimana, J., Humphreys, M., Posner, D. N., \& Weinstein, J. M. (2007). Why Does Ethnic Diversity Undermine Public Goods Provision? American Political Science Review, 101(04), 709-725.

Helbling, M., Reeskens, T., \& Stolle, D. (2015). Political Mobilisation, Ethnic Diversity and Social Cohesion: The Conditional Effect of Political Parties: Conditional Effect of Political Parties. Political Studies, 63(1), 101-122.

Hirschman, A. O. (1964). The Paternity of an Index. The American Economic Review, 54(5), 761762. 
Hou, F., \& Wu, Z. (2009). Racial Diversity, Minority Concentration, and Trust in Canadian Urban Neighborhoods. Social Science Research, 38(3), 693-716.

Kimenyi, M. S. (2006). Ethnicity, Governance and the Provision of Public Goods. Journal African Economics, 15(1), 62-99.

Koopmans, R., \& Veit, S. (2014a). Cooperation in Ethnically Diverse Neighborhoods: A Lost-Letter Experiment. Political Psychology. 35(3), 379-400.

Koopmans, R., \& Veit, S. (2014b). Ethnic Diversity, Trust, and the Mediating Role of Positive and Negative Interethnic Contact: A Priming Experiment. Social Science Research, 47, 91-107.

Koopmans, R., Lancee, B., \& Schaeffer, M. (2015). Ethnic diversity in diverse societies. An introduction. In R. Koopmans, B. Lancee \& M. Schaeffer: Social Cohesion and Immigration in Europe and North America: Mechanisms, Conditions, and Causality (p. 1-20). London: Routledge.

Koopmans, R., \& Schaeffer, M. (2016). Statistical and Perceived Diversity and Their Impacts on Neighborhood Social Cohesion in Germany, France and the Netherlands. Social Indicators Research, 125(3), 853-883.

Massey, D. S., \& Denton, N. A. (1988). The Dimensions of Residential Segregation. Social Forces, $67(2), 281-315$.

Miguel, E., \& Gugerty, M. K. (2005). Ethnic Diversity, Social Sanctions, and Public Goods in Kenya. Journal of Public Economics, 89(11-12), 2325-2368.

Montalvo, J. G., \& Reynal-Querol, M. (2005a). Ethnic Diversity and Economic Development. Journal of Development Economics, 76(2), 293-323.

Montalvo, J. G., \& Reynal-Querol, M. (2005b). Ethnic polarization, potential conflict, and civil wars. American Economic Review, 796-816.

Olzak, S. (1992). The Dynamics of Ethnic Competition and Conflict. Stanford: Stanford University Press.

Page, S. E. (2008). The Difference: How the Power of Diversity Creates Better Groups, Firms, Schools, and Societies. Princeton: Princeton University Press.

Page, S. E. (2010). Diversity and Complexity. Princeton: Princeton University Press.

Portes, A., \& Vickstrom, E. (2011). Diversity, Social Capital, and Cohesion. Annual Review of Sociology, 37, 461-479.

Putnam, R. D. (2007). E Pluribus Unum: Diversity and Community in the Twenty-First Century. Scandinavian Political Studies, 30(2), 137-174.

Rabe-Hesketh, S., \& Skrondal, A. (2008). Multilevel and Longitudinal Modeling using Stata. College Station: Stata Press.

Reardon, S. F., \& Firebaugh, G. (2002). Measures of Multigroup Segregation. Sociological Methodology, 32(1), 33-67.

Sampson, R. J., Morenoff, J. D., \& Earls, F. (1999). Beyond Social Capital: Spatial Dynamics of Collective Efficacy for Children. American Sociological Review, 64(5), 633-660.

Schaeffer, M. (2014). Ethnic Diversity and Social Cohesion: Immigration, Ethnic Fractionalization and Potentials for Civic Action. Farnham: Ashgate.

Schaeffer, M. (2013a). Can competing diversity indices inform us about why ethnic diversity erodes social cohesion? A test of five diversity indices in Germany. Social Science Research, 42(3), $755-774$. 
Schaeffer, M. (2013b). Which groups are mostly responsible for problems in your neighbourhood? Ethnic and Racial Studies, 36(1), 156-178.

Schaeffer, M., Koopmans, R., Veit, S., Wagner, M., \& Wiedner, J. (2011). The Ethnic Diversirty and Collective Action Survey (EDCAS). WZB Discussion Paper Series, No. SP IV 2011-701. Retrieved from https://www.econstor.eu/dspace/bitstream/10419/57767/1/714979910.pdf

Sethna, J. (2006). Statistical Mechanics. Oxford: Oxford University Press.

Stichnoth, H., \& Straeten, K. V. der. (2013). Ethnic Diversity, Public Spending and Individual Support for the Welfare State: A Review of the Empirical Literature. Journal of Economic Surveys, 27(2), 364-389.

Stirling, A. (2007). A General Framework for Analysing Diversity in Science, Technology and Society. Journal of The Royal Society Interface, 4(15), 707-719.

Stolle, D., Soroka, S., \& Johnston, R. (2008). When Does Diversity Erode Trust? Neighborhood Diversity, Interpersonal Trust and the Mediating Effect of Social Interactions. Political Studies, 56(1), 57-75.

Tajfel, H., \& Turner, J. C. (1986). The Social Identity Theory of Intergroup Behavior. In S. Worchel \& W. G. Austin (Eds.), Psychology of Intergroup Relations (pp. 7 - 24). Chicago: NelsonHall Publishers.

Van der Meer, T., \& Tolsma, J. (2014). Ethnic Diversity and Its Supposed Detrimental Effects on Social Cohesion. Annual Review of Sociology, 40, 459-478.

Williamson, A. F. (2015). Declining Trust Amidst Diversity? A Natural Experiment in Lewiston, Maine. In R. Koopmans, B. Lancee, \& M. Schaeffer (Eds.), Social Cohesion and Immigration in Europe and North America: Mechanisms, Conditions and Causality. London: Routledge.

Wooldridge, J. M. (2003). Cluster-Sample Methods in Applied Econometrics. The American Economic Review, 93(2), 133-138.

Zheng, T., Salganik, M. J., \& Gelman, A. (2006). How Many People do you Know in Prison? Using Overdispersion in Count Data to Estimate Social Structure in Networks. Journal of the American Statistical Association, 101(474), 409-423. 
Table A1 Relational diversity as predictor of neighborhood cohesion across 55 German cities and regions, full model

\begin{tabular}{|c|c|c|c|c|}
\hline & $\begin{array}{c}\text { Trust in } \\
\text { neighbors }\end{array}$ & $\begin{array}{l}\text { Collective } \\
\text { efficacy }\end{array}$ & $\begin{array}{c}\text { Lack of } \\
\text { social problems }\end{array}$ & $\begin{array}{l}\text { Neighborhood } \\
\text { cohesion scale }\end{array}$ \\
\hline \multirow[t]{2}{*}{ In-group share } & $0.451^{* * *}$ & $0.517^{\text {**** }}$ & $0.483^{* *}$ & $0.644^{* * *}$ \\
\hline & $(0.072)$ & $(0.087)$ & $(0.177)$ & $(0.115)$ \\
\hline \multirow[t]{2}{*}{ *Immigrant origin } & -0.428 & -0.016 & -0.252 & -0.240 \\
\hline & $(0.276)$ & $(0.300)$ & $(0.453)$ & $(0.337)$ \\
\hline \multirow{2}{*}{ Relational (out-group) Entropy ${ }^{0.5}$} & -0.042 & $-0.102^{* *}$ & -0.076 & $-0.103^{* *}$ \\
\hline & $(0.026)$ & $(0.037)$ & $(0.051)$ & $(0.034)$ \\
\hline \multirow[t]{2}{*}{ *Immigrant origin } & $-0.174^{*}$ & $-0.202^{*}$ & -0.171 & $-0.245^{*}$ \\
\hline & $(0.074)$ & $(0.088)$ & $(0.124)$ & $(0.108)$ \\
\hline \multirow[t]{2}{*}{ Local unemployment rate } & $-0.052^{* * *}$ & $-0.071^{* * *}$ & $-0.102^{* * *}$ & $-0.098^{* * *}$ \\
\hline & $(0.010)$ & $(0.016)$ & $(0.029)$ & $(0.021)$ \\
\hline \multirow[t]{2}{*}{ Population density } & $0.038^{*}$ & 0.023 & -0.028 & 0.014 \\
\hline & $(0.015)$ & $(0.024)$ & $(0.052)$ & $(0.035)$ \\
\hline \multirow[t]{2}{*}{ Age (in 10 years) } & $0.064^{* * *}$ & -0.006 & $0.072^{* * *}$ & $0.045^{* * *}$ \\
\hline & $(0.010)$ & $(0.008)$ & $(0.007)$ & $(0.008)$ \\
\hline \multicolumn{5}{|l|}{ Education, reference: Low } \\
\hline \multirow[t]{2}{*}{ Medium education } & 0.055 & 0.034 & 0.036 & 0.055 \\
\hline & $(0.041)$ & $(0.047)$ & $(0.058)$ & $(0.045)$ \\
\hline \multirow[t]{2}{*}{ High education } & $0.147^{* *}$ & 0.057 & 0.031 & 0.095 \\
\hline & $(0.044)$ & $(0.052)$ & $(0.065)$ & $(0.049)$ \\
\hline \multirow[t]{2}{*}{ Employed } & 0.025 & $0.064^{* *}$ & 0.024 & $0.056^{*}$ \\
\hline & $(0.025)$ & $(0.020)$ & $(0.026)$ & $(0.021)$ \\
\hline \multirow[t]{2}{*}{ Residence in the neighborhood (in 10 years) } & $0.049^{* * *}$ & 0.014 & $-0.030^{* * *}$ & 0.012 \\
\hline & $(0.007)$ & $(0.008)$ & $(0.006)$ & $(0.006)$ \\
\hline \multirow[t]{2}{*}{ Home owner } & $0.224^{* * *}$ & $0.316^{* * *}$ & $0.280^{* * *}$ & $0.370^{* * *}$ \\
\hline & $(0.021)$ & $(0.030)$ & $(0.025)$ & $(0.027)$ \\
\hline \multirow[t]{2}{*}{ Female } & $0.059^{* *}$ & $0.084^{* * *}$ & $0.135^{* * *}$ & $0.126^{* * *}$ \\
\hline & $(0.022)$ & $(0.021)$ & $(0.024)$ & $(0.022)$ \\
\hline \multirow[t]{2}{*}{ East Germany } & 0.029 & 0.060 & 0.064 & 0.072 \\
\hline & $(0.037)$ & $(0.044)$ & $(0.064)$ & $(0.053)$ \\
\hline \multirow[t]{2}{*}{ Married } & $0.160^{* * * *}$ & $0.137^{* * *}$ & 0.019 & $0.141^{* * *}$ \\
\hline & $(0.021)$ & $(0.022)$ & $(0.025)$ & $(0.023)$ \\
\hline \multicolumn{5}{|l|}{ Religion, reference: Atheist } \\
\hline \multirow[t]{2}{*}{ Protestant } & $0.159^{* * *}$ & $0.143^{* * *}$ & -0.045 & $0.118^{* * *}$ \\
\hline & $(0.029)$ & $(0.035)$ & $(0.030)$ & $(0.030)$ \\
\hline \multirow[t]{2}{*}{ Catholic } & $0.084^{*}$ & $0.057^{*}$ & 0.000 & $0.061^{*}$ \\
\hline & $(0.034)$ & $(0.027)$ & $(0.030)$ & $(0.028)$ \\
\hline \multirow[t]{2}{*}{ Muslim } & 0.013 & -0.015 & 0.105 & 0.037 \\
\hline & $(0.052)$ & $(0.046)$ & $(0.068)$ & $(0.052)$ \\
\hline \multirow[t]{2}{*}{ Other } & 0.002 & -0.027 & -0.036 & -0.030 \\
\hline & $(0.057)$ & $(0.061)$ & $(0.038)$ & $(0.054)$ \\
\hline \multirow[t]{2}{*}{ Immigrant origin } & -0.049 & 0.601 & 0.433 & 0.525 \\
\hline & $(0.350)$ & $(0.354)$ & $(0.498)$ & $(0.358)$ \\
\hline \multirow[t]{2}{*}{ 2nd generation } & 0.050 & -0.045 & $-0.151^{* *}$ & -0.070 \\
\hline & $(0.042)$ & $(0.034)$ & $(0.046)$ & $(0.036)$ \\
\hline Constant & $-1.036^{* * *}$ & $-0.723^{* * *}$ & $-0.923^{* * *}$ & $-1.135^{* * *}$ \\
\hline & $(0.097)$ & $(0.083)$ & $(0.139)$ & $(0.090)$ \\
\hline $\mathrm{N}$ & 7888 & 7888 & 7888 & 7888 \\
\hline
\end{tabular}

Cluster-robust standard errors in parentheses, $p<0.05,{ }^{* *} p<0.01,{ }^{* * *} p<0.001$ 
Table A2 Relational diversity as predictor of neighborhood cohesion across 55 German cities and regions, robustness analyses

\begin{tabular}{|c|c|c|c|c|}
\hline & $\begin{array}{c}\text { Trust in } \\
\text { neighbors }\end{array}$ & $\begin{array}{l}\text { Collective } \\
\text { efficacy }\end{array}$ & $\begin{array}{c}\text { Lack of } \\
\text { social problems }\end{array}$ & $\begin{array}{l}\text { Neighborhood } \\
\text { cohesion scale }\end{array}$ \\
\hline \multirow[t]{2}{*}{ In-group share } & $0.423^{* * *}$ & $0.466^{* * *}$ & $0.378^{*}$ & $0.562^{* * *}$ \\
\hline & $(0.087)$ & $(0.098)$ & $(0.153)$ & $(0.117)$ \\
\hline \multirow[t]{2}{*}{ *Immigrant origin } & -0.131 & 0.293 & -0.221 & 0.052 \\
\hline & $(0.301)$ & $(0.313)$ & $(0.463)$ & $(0.351)$ \\
\hline \multirow{2}{*}{ Relational (out-group) Entropy ${ }^{0.5}$} & -0.046 & $-0.103^{* *}$ & -0.053 & $-0.096^{* *}$ \\
\hline & $(0.025)$ & $(0.036)$ & $(0.040)$ & $(0.033)$ \\
\hline \multirow[t]{2}{*}{ *Immigrant origin } & -0.110 & -0.151 & $-0.249^{*}$ & $-0.225^{*}$ \\
\hline & $(0.077)$ & $(0.090)$ & $(0.109)$ & $(0.102)$ \\
\hline \multirow[t]{2}{*}{ Local unemployment rate } & $-0.050^{* * *}$ & $-0.069^{* * *}$ & $-0.097^{* * *}$ & $-0.095^{* * *}$ \\
\hline & $(0.010)$ & $(0.016)$ & $(0.021)$ & $(0.019)$ \\
\hline \multirow[t]{2}{*}{ Population density } & 0.009 & -0.001 & 0.052 & 0.023 \\
\hline & $(0.025)$ & $(0.036)$ & $(0.053)$ & $(0.044)$ \\
\hline \multirow[t]{2}{*}{ Age (in 10 years) } & $0.065^{* * *}$ & -0.007 & $0.051^{* * *}$ & $0.036^{* * *}$ \\
\hline & $(0.010)$ & $(0.009)$ & $(0.007)$ & $(0.008)$ \\
\hline \multicolumn{5}{|l|}{ Education, reference: Low } \\
\hline \multirow[t]{2}{*}{ Medium education } & 0.022 & 0.003 & 0.022 & 0.020 \\
\hline & $(0.042)$ & $(0.048)$ & $(0.057)$ & $(0.045)$ \\
\hline \multirow[t]{2}{*}{ High education } & $0.104^{*}$ & 0.018 & 0.043 & 0.063 \\
\hline & $(0.044)$ & $(0.052)$ & $(0.065)$ & $(0.048)$ \\
\hline \multirow[t]{2}{*}{ Employed } & 0.014 & $0.055^{* *}$ & 0.025 & $0.048^{*}$ \\
\hline & $(0.025)$ & $(0.020)$ & $(0.028)$ & $(0.021)$ \\
\hline \multirow[t]{2}{*}{ Residence in the neighborhood (in 10 years) } & $0.046^{* * *}$ & 0.011 & $-0.036^{* * *}$ & 0.007 \\
\hline & $(0.007)$ & $(0.008)$ & $(0.006)$ & $(0.006)$ \\
\hline \multirow[t]{2}{*}{ Home owner } & $0.214^{* * *}$ & $0.305^{* * *}$ & $0.247^{* * *}$ & $0.347^{* * *}$ \\
\hline & $(0.021)$ & $(0.031)$ & $(0.025)$ & $(0.028)$ \\
\hline \multirow[t]{2}{*}{ Female } & $0.060^{* *}$ & $0.084^{* * *}$ & $0.125^{* * *}$ & $0.122^{* * *}$ \\
\hline & $(0.022)$ & $(0.021)$ & $(0.024)$ & $(0.022)$ \\
\hline \multirow[t]{2}{*}{ East Germany } & 0.053 & 0.075 & -0.038 & 0.047 \\
\hline & $(0.041)$ & $(0.048)$ & $(0.052)$ & $(0.053)$ \\
\hline \multirow[t]{2}{*}{ Married } & $0.154^{* * *}$ & $0.132^{* * *}$ & 0.026 & $0.139^{* * *}$ \\
\hline & $(0.021)$ & $(0.023)$ & $(0.025)$ & $(0.023)$ \\
\hline \multicolumn{5}{|l|}{ Religion, reference: Atheist } \\
\hline \multirow[t]{2}{*}{ Protestant } & $0.160^{* * *}$ & $0.145^{* * *}$ & -0.038 & $0.123^{* * *}$ \\
\hline & $(0.029)$ & $(0.035)$ & $(0.030)$ & $(0.031)$ \\
\hline Catholic & $0.088^{*}$ & $0.060^{*}$ & 0.000 & $0.064^{*}$ \\
\hline & $(0.034)$ & $(0.026)$ & $(0.030)$ & $(0.027)$ \\
\hline Muslim & 0.055 & 0.026 & 0.122 & 0.082 \\
\hline & $(0.052)$ & $(0.047)$ & $(0.067)$ & $(0.051)$ \\
\hline Other & 0.007 & -0.019 & -0.010 & -0.014 \\
\hline & $(0.058)$ & $(0.063)$ & $(0.040)$ & $(0.055)$ \\
\hline Immigrant origin & -0.146 & 0.436 & -0.323 & 0.092 \\
\hline & $(0.368)$ & $(0.365)$ & $(0.493)$ & $(0.356)$ \\
\hline 2nd generation & 0.015 & $-0.080^{*}$ & $-0.178^{* * *}$ & $-0.113^{* *}$ \\
\hline & $(0.042)$ & $(0.033)$ & $(0.047)$ & $(0.036)$ \\
\hline Abs. number of foreign nationals (in 1000) & 0.022 & 0.019 & $-0.068^{*}$ & -0.009 \\
\hline & $(0.018)$ & $(0.022)$ & $(0.027)$ & $(0.025)$ \\
\hline Inter-ethnic nbh acquaintances & 0.001 & -0.003 & $-0.027^{* * *}$ & $-0.012^{*}$ \\
\hline & $(0.005)$ & $(0.005)$ & $(0.005)$ & $(0.005)$ \\
\hline *Immigrant origin & $0.036^{* * *}$ & $0.038^{* * *}$ & $0.069^{* * *}$ & $0.062^{* * *}$ \\
\hline & $(0.010)$ & $(0.008)$ & $(0.008)$ & $(0.009)$ \\
\hline Inter-ethnic nbh encounters & 0.018 & 0.001 & $-0.128^{* * *}$ & $-0.046^{* * *}$ \\
\hline & $(0.012)$ & $(0.012)$ & $(0.014)$ & $(0.011)$ \\
\hline *Immigrant origin & $0.053^{*}$ & $0.067^{* * *}$ & $0.081^{* * * *}$ & $0.090^{* * * *}$ \\
\hline & $(0.024)$ & $(0.019)$ & $(0.023)$ & $(0.021)$ \\
\hline Constant & $-1.002^{* * *}$ & $-0.622^{* * *}$ & $-0.397^{* *}$ & $-0.851^{* * *}$ \\
\hline & $(0.118)$ & $(0.089)$ & $(0.130)$ & $(0.099)$ \\
\hline $\mathrm{N}$ & 7888 & 7888 & 7888 & 7888 \\
\hline
\end{tabular}


Figure A1 Accuracy of respondents' average estimates of the percentage of persons of immigrant origin

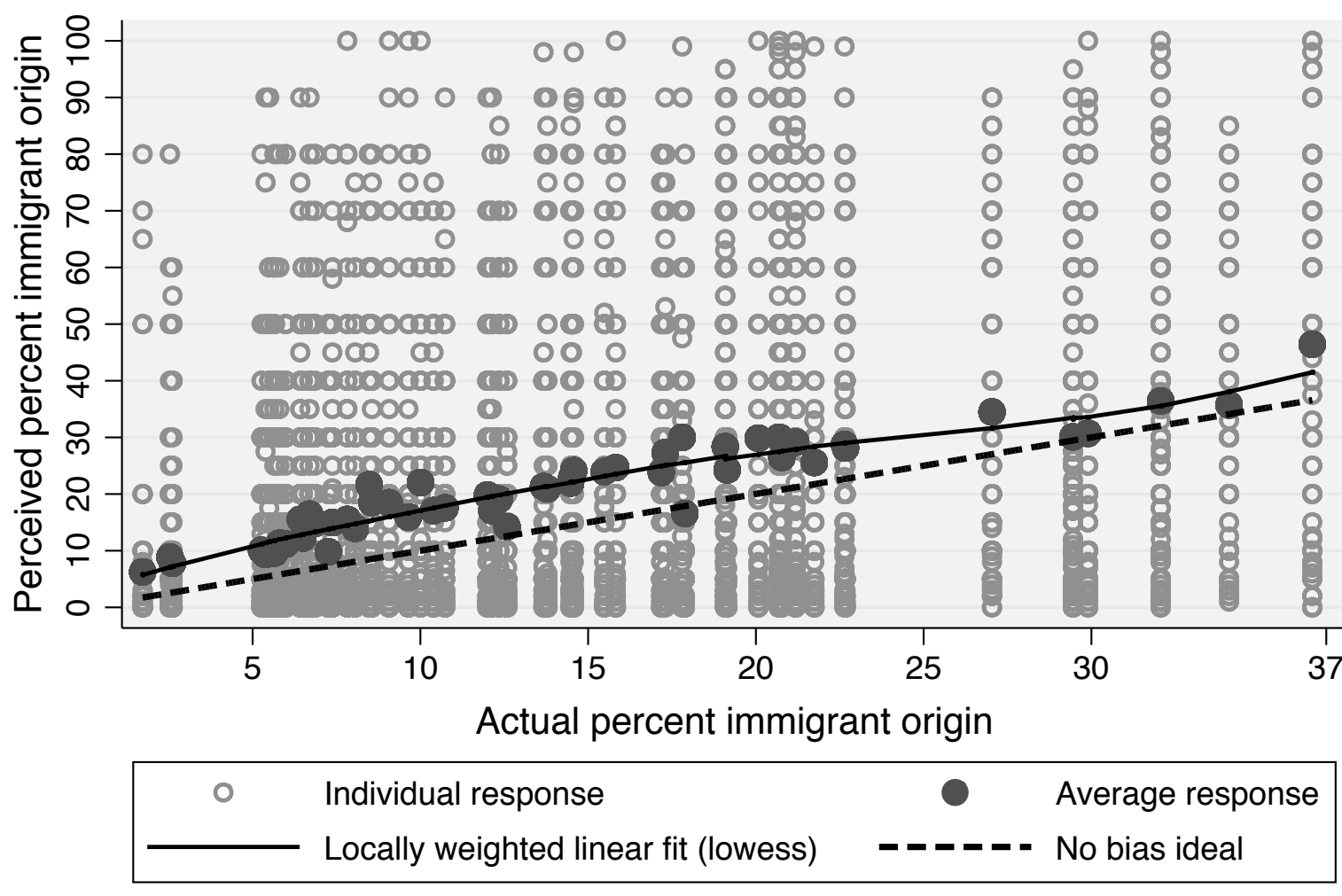

